\title{
Increasing students Engagement during Virtual Classroom Teaching through Effective use of Online Tools
}

\author{
Ms. Varsha T.Lokare ${ }^{1}$, Dr. A. W. Kiwelekar ${ }^{2}$, Ms. Sapana S. Barphe ${ }^{3}$, , Dr. L. D. Netak ${ }^{4}$, Mr. \\ P.M.Jadhav 5 \\ ${ }^{1}$ Rajarambapu Institute of Technology, Sakharale, Affiliated to Shivaji University, Kolhapur, Maharashtra and Research \\ Scholar, Dr. Babasaheb Ambedkar Technological University, Lonere, Raigad Maharashtra \\ 2,3,4, Dr. Babasaheb Ambedkar Technological University, Lonere, Raigad Maharashtra \\ ${ }^{5}$ Rajarambapu Institute of Technology, Sakharale, Affiliated to Shivaji University, Kolhapur, Maharashtra \\ ${ }^{1}$ varsha.lokare@ ritindia.edu \\ $\left\{{ }^{2}\right.$ awk, ${ }^{3}$ ssbarphe, , ${ }^{4}$ ldnetak $\} @$ dbatu.ac.in \\ ${ }^{5}$ prakash.jadhav@ritindia.edu
}

\begin{abstract}
Nowadays, the entire world is facing the problem of pandemic i.e. COVID-19. Hence it is a challenging task for educators to engage students during virtual classroom activity. Many online tools are available to take instant feedback from students to measure their involvement levels like Quizzes, Polls, Surveys, etc. Hence, in this paper, the use of two online tools like InterviewBit and Slido is being addressed. These online tools are used to ask the questions during online lecture delivery that may help in measuring the overall involvement of the students. The mentioned tools are described in detail along with its incorporation in teaching Data Structure and Algorithms course for second year B. Tech in Computer Engineering students (around 120 Students). Also, the learning of students before and after the usage of the Tools have been compared and analysed. It has been observed that there is approximately $20 \%$ improvement in the overall learning outcomes after the usage of the Tools. Also, the cognitive and affective learning domains are considered to measure the overall impact.
\end{abstract}

Keywords: InterviewBit, Slido, virtual classroom activity.

\section{INTRODUCTION}

A virtual environment has its own advantages and limitations as compared to the physical classroom environment. To ensure student engagement during online classroom activity is a challenging task. Hence, in this paper total six online Tools have been discussed, namely: InterviewBit[1] and Slido[2]. Here, Data Structure and Algorithms (DSA) course has been considered as a case study to apply above mentioned online tools. This course is for second year B. Tech students in Computer Engineering department. As shown in Figure1, during the course teaching in virtual platform using Microsoft Teams Learning Management System [3] (LMS), various tools have been applied to check the engagement of the students. The details of activity plan for each online tool are explained in the next section. The second section covers the result analysis part and concluding remarks are given in the last section.

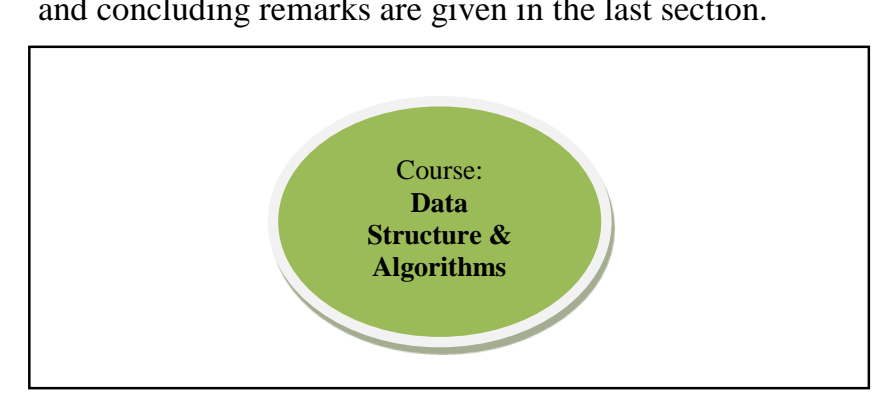

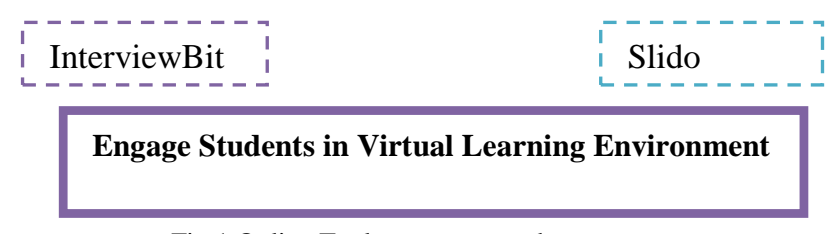

Fig.1 Online Tools to ensure students engagement

\section{ONLINE TOOLS}

There are many online tools available to assess students on the distance education platform. Many researchers [4-7] had contributed their work for the tool-based learning approach. On the physical classroom environment as face to face conversation is possible, it is easy for instructors to get live feedback from students. Hence, the instructor may change his/her teaching strategy as per the responses received. But in online mode, there are many limitations like it is difficult for an instructor to predict the percentage of concept understood by the students. The below list of online tools may help instructor to measure the student involvement during the online classroom teaching activity. Here, the details of the tool used along with its application to teach DSA course is being explained. 


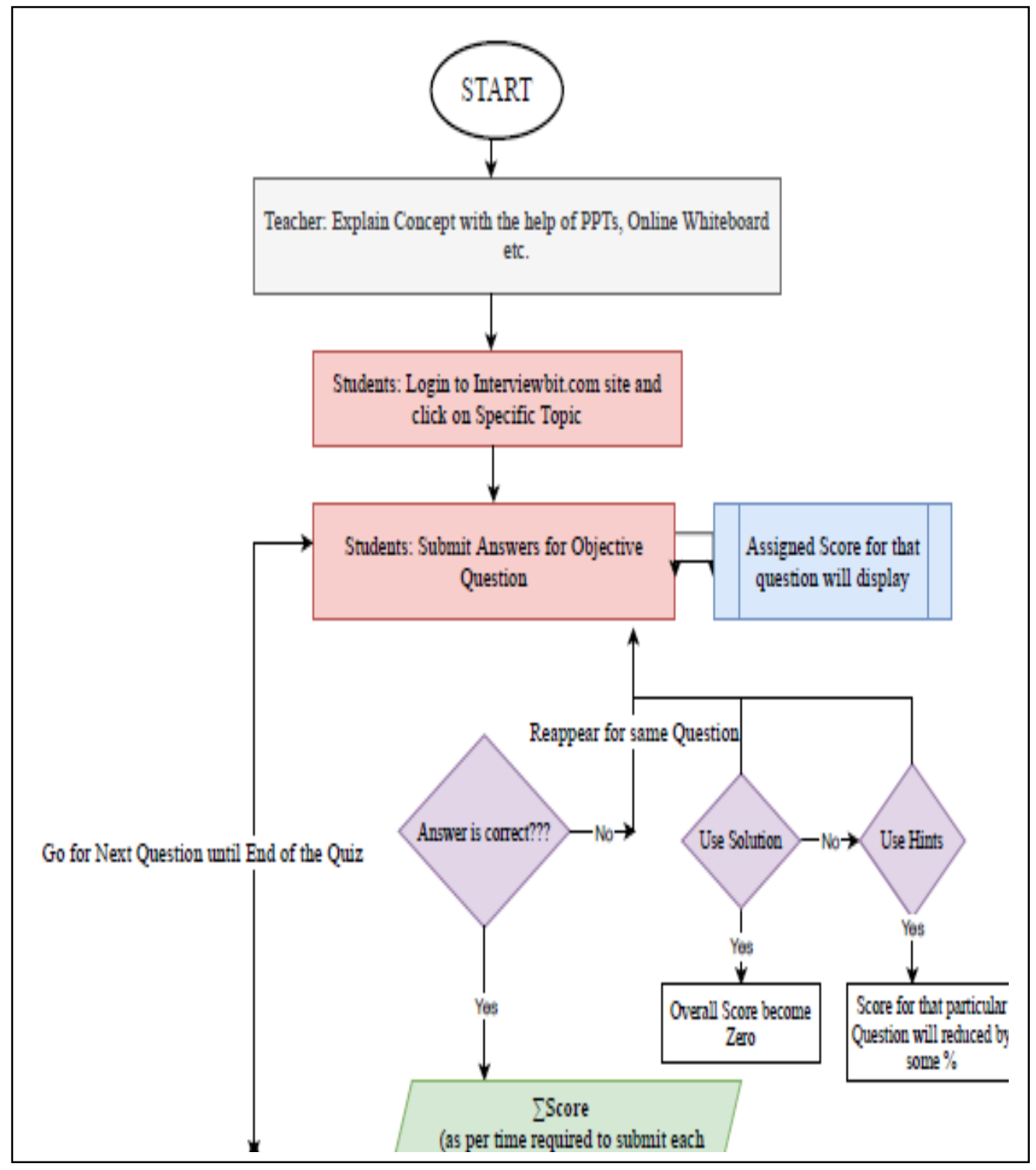




\section{Tool 1: InterviewBit}

The Interview Bit tool is available on below mentioned link: https://www.interviewbit.com/courses/

This is helpful for the students to practice objective questions along with programming, problem solving questions that are mostly asked in placement drives of many multinational companies.

\section{Activity Plan}

\begin{tabular}{|l|l|l|}
\hline Teachers Role & Students Role & Duration \\
\hline $\begin{array}{l}\text { Explain the Concept on } \\
\text { virtual environment }\end{array}$ & $10 \mathrm{~min}$ \\
\hline $\begin{array}{l}\text { Ask students to go for Slido } \\
\text { tab on MsTeams }\end{array}$ & $\begin{array}{l}\text { Open the Slido Tab in } \\
\text { MsTeams }\end{array}$ & $2 \mathrm{~min}$ \\
\hline $\begin{array}{l}\text { Post Question in Q/A } \\
\text { section }\end{array}$ & Solve and Type Answer & $5 \mathrm{~min}$ \\
\hline
\end{tabular}

As shown in Fig.2, InterviewBit Tool activity is carried out. The Instructor need to discuss a particular topic and then ask students to appear for multiple choice questionnaire and provide time as per complexity and total number of questions in a particular section. This particular tool is helpful in which first attempt does not provide any hint and as per time taken to answer, score will be given. All the questions asked to practice as well as for the contest, are totally based on the previous questions asked in placement drives of well known companies. Hence, this tool not only helps in better understanding of the concept bit also prepare students for placement activities. The screenshot of sample questionnaires is as shown in Figure4.

\section{Tool 2: Slido}

In a virtual environment, instructor can able to take live polls along with quizzes. Students also can ask questions in Q/A section, present in Slido tool. In MsTeams Learning management system, Slido tool is available or one can explicitly go to www.slido.com website, do registration and Create live interaction in Q/A section. As shown in Figure 3 and Figure5, live responses are collected during the session. It is observed that this tool is very useful to analyse the understanding of the students quickly in the virtual classroom teaching environment. Also, students can able to ask their doubts in Q/A section. The Live polling facility is also helpful in checking the learning and overall involvement of the students.

\section{Activity Plan}

\begin{tabular}{|l|l|l|}
\hline Teachers Role & Students Role & Duration \\
\hline $\begin{array}{l}\text { Explain the Concept on } \\
\text { virtual environment }\end{array}$ & $10 \mathrm{~min}$ \\
\hline $\begin{array}{l}\text { Ask students to go for } \\
\text { InterviewBit }\end{array}$ & $\begin{array}{l}\text { Open below link: } \\
\text { https://www.interviewbit.co } \\
\mathrm{m} / \text { courses/ }\end{array}$ & $2 \mathrm{~min}$ \\
\hline $\begin{array}{l}\text { Ask students to share } \\
\text { score }\end{array}$ & Solve Questions & $15 \mathrm{~min}$ \\
\hline $\begin{array}{l}\text { Announce first three } \\
\text { Toppers }\end{array}$ & & $5 \mathrm{~min}$ \\
\hline
\end{tabular}

To use this activity in specific courses, the instructor must have to register first at slido.com while no registration is required for participants. Multiple options are available like Quiz, live polls, Q/A etc.

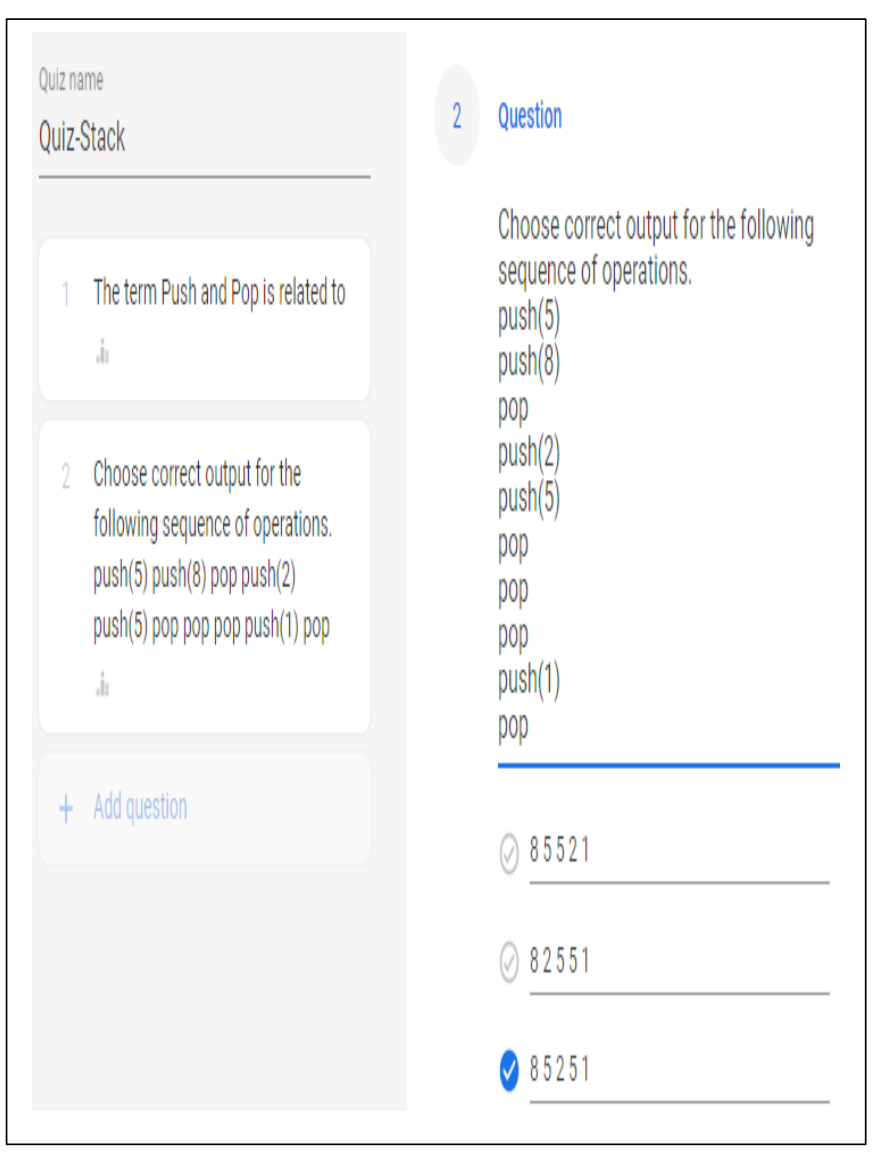

Fig.3 Screenshot of live poll created on Slido 


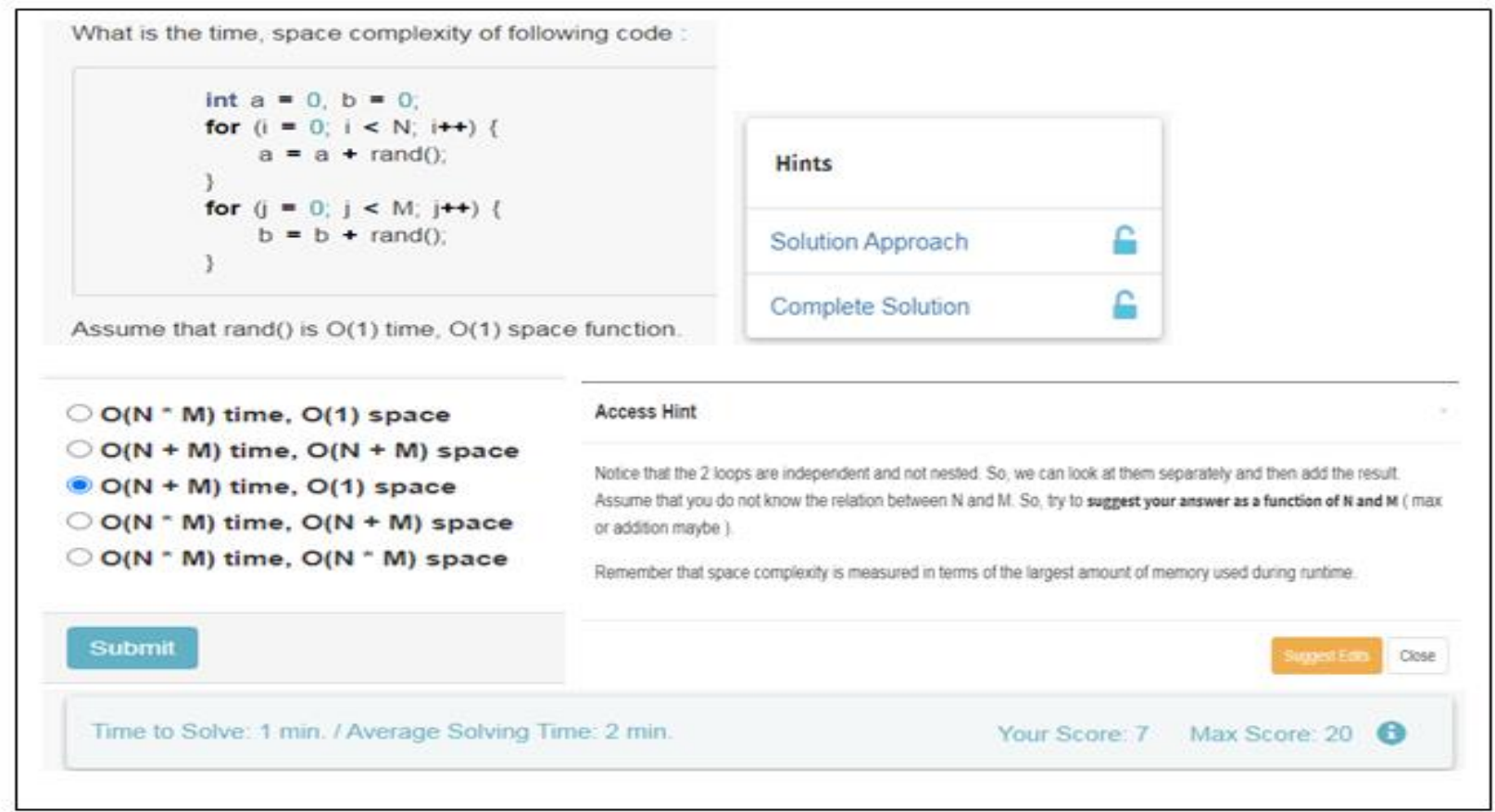

Fig.4: Screenshot of Sample Questions asked in InterviewBit

M Manasi Pawar 1903058 Aug 24, 2020

abcde*t/-

S Sakshi chougule

Aug 24, 2020

abcde*t/-

S Sheetal Khavare

abcde*+/-

24.2020

\section{은 1903032}

Aug 24, 2020

abcde*+/-

A linear list of elements in which deletion can be done from one end (front) and insertion can take place only at the other end (rear) is known as a?

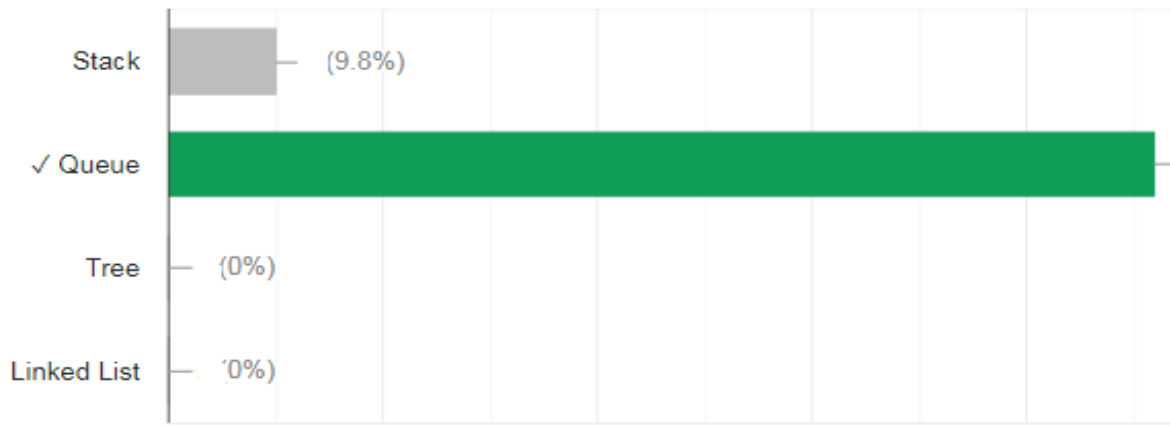

Fig.5 Screenshot of live Responses collected using Slido 


\section{RESULT ANALYSIS}

Affective learning is relating to the student's responsiveness approach, i.e. listening carefully and responding actively. To measure the students understanding in the online platform, affective and cognitive [8] approach need to be considered. For example, cognitive learning analysis can be done with the help of marks scored in examinations. Affective learning analysis may relate with how students listening and responding to the questions. As shown in Figure 6, as a case study Linked List data structure is being considered. Total numbers of responses received along with its accuracy are the parameters considered here for measuring affective learning of the students. Also, for cognitive learning analysis, questions based on various Blooms Taxonomy levels were asked.

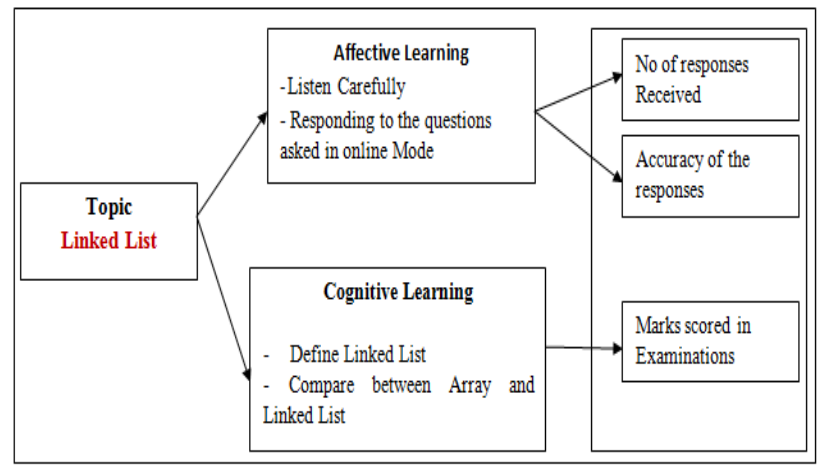

Fig. 6 Affective and Cognitive learning

\section{Observations \& Result Analysis:}

To engage students in an online environment, total two tools were used namely interviewBit and Slido. The responses of the students before applying this tool and after application of these tools have been recorded as shown in Table1. Also, to measure the cognitive learning, total two tests had conducted before and after the application of tools. On an average response are considered and mapping with average marks is done before and after the usage of the online Tools. I.e. Initially, Chat Box was used for taking live responses from the students at virtual classroom activity. It is observed that only $18 \%$ students had responded. After that to measure the cognitive learning of the students, Objective Test has been conducted.

Participants: 120 Students

Class: Second Year B. Tech ( Div.: A and B)

Course: Data Structure \& Algorithms

To calculate the cognitive learning average marks before and after the usage of online tools is considered here. Following formulae is used to measure the overall improvement in the marks:

Improvement $=\frac{\text { AvgM_ObjT2 }}{\text { Total Marks }} \times 100-\frac{\text { AvgM_ObjT1 }}{\text { Total Marks }} \times 100$

Where,

AvgM_ObjT1 : Average of marks scored by 120 students in Objective Test 1

AvgM_ObjT2 : Average of marks scored by 120 students in Objective Test 2

Total Marks: 20
Improvement in result is $90 \%-70 \%=20 \%$.

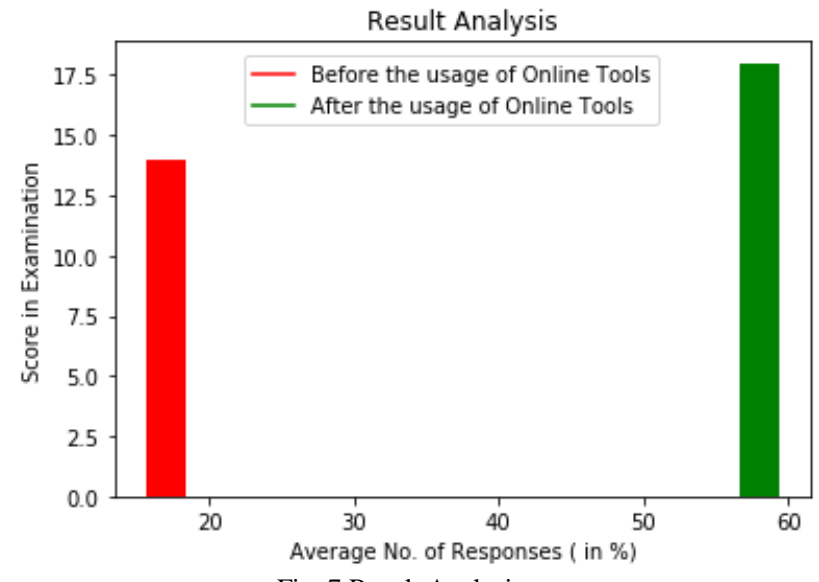

Fig. 7 Result Analysis

Hence, from Figure 7 it is observed that there is a relation between the responsiveness of the students in a virtual classroom and marks scored in the examinations. As number of responses increases, the student engagement also proportionally increased. That in turn results in improvement in the marks in the examination.

Table 1. Result Analysis

\section{CONCLUSION}

\begin{tabular}{|c|c|c|c|}
\hline \multirow{2}{*}{\multicolumn{2}{|c|}{$\begin{array}{l}\text { Affective Learning } \\
\text { Average No. of Students } \\
\text { responded (in \%) }\end{array}$}} & \multicolumn{2}{|c|}{ Cognitive Learning } \\
\hline & & Examination & $\begin{array}{c}\text { Average } \\
\text { Marks }\end{array}$ \\
\hline $\begin{array}{l}\text { Using Chat Box in } \\
\text { MsTeams }\end{array}$ & 18 & $\begin{array}{l}\text { Objective } \\
\text { Test1 }\end{array}$ & 14 \\
\hline \multicolumn{4}{|c|}{ After the usage of Online Tools } \\
\hline InterviewBit & 52 & \multirow{2}{*}{$\begin{array}{l}\text { Objective } \\
\text { Test } 2\end{array}$} & \multirow[t]{2}{*}{18} \\
\hline Slido & 80 & & \\
\hline
\end{tabular}

To ensure students engagement in a virtual classroom, many online tools are available. In this paper, InterviewBit and Slido these two free online tools application has been demonstrated. Along with that, Chat Box in MsTeams has also used to collect online responses from the students. Here, Data Structure \& Algorithms course along with total 120 students is being considered for study purpose. It is observed that the average number of responses received from the students have increased by applying online tools. Also, the average marks secured by the students are increased around $20 \%$. This work can be extended by applying other online tools like Poll Everywhere, Answer Garden etc. 


\section{REFERENCES}

[1] www.interviewbit.com/courses/

[2] www.slido.com

[3]www.microsoft.com/en-in/microsoft-365/microsoft-

teams/group-chat-software

[4] Allen, I. E. and Seaman, J. (2003) Sizing the Opportunity:

The Quality and Extent of Online Education in the United

States. 2003 and 2003 Needham, MA: Sloan Center for

Online Education

[5] Book: Carla Haelermans, Digital Tools in Education On Usage, Effects and the Role of the Teacher, 2017.

[6] Ms. Varsha T.Lokare, Mrs. Gautami Shingan, Mr. Prakash Jadhav, Dr. N.V.Dharwadkar, "Effective Use of Online Tools to Prepare Students for Competitive Examinations", Journal of Engineering Education Transformations,2020.Harasim, L. (ed.) (1990) Online Education: Perspectives on a New Environment New York: Praeger

[8]Baker J.D. (2012) Affective and Cognitive Learning in the Online Classroom. In: Seel N.M. (eds) Encyclopedia of the Sciences of Learning. Springer, Boston, MA. https://doi.org/10.1007/978-1-4419-1428-6_762 